\title{
Receptive Vocabulary Size of Male and Female Saudi English Major Graduates
}

\author{
Ibrahim R. Alqarni ${ }^{1}$ \\ ${ }^{1}$ Department of English Language and Translation, College of Languages and Translation, King Saud University, \\ Riyadh, Saudi Arabia \\ Correspondence: Ibrahim R. Alqarni, Department of English Language and Translation, College of Languages \\ and Translation, King Saud University, Riyadh, Saudi Arabia. E-mail: irqarni@ksu.edu.sa
}

$\begin{aligned} & \text { Received: September 20, } 2018 \quad \text { Accepted: October 16, } 2018 \quad \text { Online Published: December 29, } 2018 \\ & \text { doi:10.5539/ijel.v9n1p111 }\end{aligned}$ URL: https://doi.org/10.5539/ijel.v9n1p111

\begin{abstract}
This study measured Saudi university students' receptive vocabulary knowledge towards the end of their final semester. The subjects were 71 Saudi male and female students. The Vocabulary Levels Test, adopted from Nation's (2008), was administered in this study. The test assesses learners' receptive knowledge of word meaning at the following distinct vocabulary levels: the $2^{\text {nd }} 1,000$-word level, the $3^{\text {rd }} 1,000$-word level, the $5^{\text {th }}$ 1,000-word level, the $10^{\text {th }} 1,000$-word level, and the Academic Word List (AWL). The results showed different participants' performance at different word levels with decreasing mean scores as the frequency of word levels decreased. The results also showed, with no exception, that males outperformed females with statistically significant differences in all the five sections of the test. The participants' average vocabulary size is approximately 876 and 799 words in the $2^{\text {nd }} 1,000$-word level, 436 and 355 words in the AWL, 725 and 590 words in the $3^{\text {rd }} 1,000$-word level, 580 and 477 words in the $5^{\text {th }} 1,000$-word level for males and females respectively. However, the average vocabulary size decreased dramatically in the $10^{\text {th }} 1,000$-word level to 254 words for males and 124 for females. Based on these findings, it is concluded that Saudi English Language and Translation university graduates, even with large vocabulary size in the high frequency bands, are generally still below the level of the desired vocabulary competency as EFL learners, and are in fact, in need for more support and concentration in their undergraduate study with regard to their vocabulary learning.
\end{abstract}

Keywords: King Saud University, receptive vocabulary, Saudi students, vocabulary size, learning strategies

\section{Introduction}

Until recent years, the teaching and learning of vocabulary items have received relatively little attention in English as a Second/Foreign Language (ESL/EFL) research and pedagogical theory. For a long time, vocabulary items were considered incidental to what was felt to be the main purpose of language teaching, namely the acquisition of grammatical knowledge. At the present time, however, researchers and teacher trainers have begun to focus their attention on lexical aspects of L2. In this view, the acquisition of an adequate vocabulary is seen as an essential component for successful second language use, playing an important role in all four language skills. Furthermore, the importance of lexical items in L2 acquisition is also recognized by many linguists and methodologists (e.g., Wilkins, 1972; Allen, 1983; Nation, 1990, 2010. 2013; Oxford, 1990; Harmer, 1996; Schmitt 2000, 2010, 2012). Harmer (1996) for example, states

If language structures make up the skeleton of language, then it is the vocabulary that provides the vital organs and the flesh (p. 153).

According to Meara, vocabulary size can be defined as the number of words in a language for which an individual has at least a basic form-meaning mapping knowledge (Meara, 1996). Recent studies have shown that vocabulary size has played a crucial role in L2 learning and large vocabulary sizes are a must to function successfully in English (e.g., Nation, 2006; Schmitt \& Schmitt, 2012). Vocabulary size is also often used as an indication of general proficiency in language acquisition research, where vocabulary size scores have been shown to highly correlate with scores in general proficiency tests (Alderson, 2005; Nation, 2013). Therefore, one can conclude that, in any language program, it is of great importance to measure both productive and receptive vocabulary sizes. 


\section{Literature Review}

One of the earliest studies in the Saudi context was Al-Hazemi's study (1993). Al-Hazemi examined the vocabulary size of military cadets at King Abdulaziz Military Academy in Saudi Arabia. The subjects were 137 males. Meara and Buxton's Eurcentres Vocabulary Test (EVST) was used in this study. The test was based on the frequencies of the most common words in English and has a yes/no format. To control guessing, the test has some unreal English words. The researcher concluded that, although a 1993 syllabus document showed that the Ministry of Education hoped that public school students would leave high school with a vocabulary size of 3,000 words, the scores of his postsecondary school subjects were below the 1000-word level, with the highest ten scores ranging from 737 to 917 words.

In similar context, Al-Nujaidi (2003) examined the relationship between vocabulary size, reading strategies, and reading comprehension of EFL learners in the Saudi context. The participants were 226 Saudi male (109) and female (117) EFL learners majoring in English or English-related programs in seven higher educational institutions in the central region of Saudi Arabia. Among other things, this study provided estimates of participants' receptive vocabulary knowledge using Nation's (1990) Vocabulary Levels Test (VLT). The complete VLT test has five sections. However, only three different word frequency levels were tested in this study: the $2^{\text {nd }} 1,000$ and $3^{\text {rd }} 1,000$ word levels, and the Academic Word List (AWL). The results showed that the learners' average vocabulary size is approximately between 500 and 700 words at the $2^{\text {nd }} 1,000$ and $3^{\text {rd }} 1,000$ word levels and around 75 words at the academic vocabulary level. The researcher concluded that the estimated vocabulary size of Saudi EFL first-year university students is rather small (p.128).

In a more recent empirical study, Al-Masrai and Milton (2012) tested the vocabulary knowledge of 92 male Saudi EFL university students near the start and near the end of their university studies. They used two tests in testing the participants' vocabulary size: the well-established Eurocentres Vocabulary Size Test (EVST) (Meara \& Jones, 1990) and the newly created XK_Lex test (Al-Masrai, 2009). Their results suggested that the Saudi university students' vocabulary size is about 2000 to 3000 words upon entry to university and around 5000 words near their graduation. The authors stated that "these figures emphasize that Saudi university learners' level is, on average, some way short of the kind of level associated with complete fluency in EFL" (p. 13). Consequently, they concluded that further English language support is needed for the undergraduates.

In a different learning context, Canga Alonso (2013) investigated the pedagogical implications of receptive vocabulary knowledge on students' understanding of written and spoken English discourse. In this regard, the researcher tested 49 females and 43 males. They were Spanish EFL students in a secondary school located in the North of Spain. He used the 2,000 frequency band of VLT (Schmitt, Schmitt \& Clapham, 2001, version 2) as the instrument to measure students' receptive vocabulary knowledge. The findings revealed a mean score of females' receptive vocabulary size below 900 words, whereas the mean score for males was slightly above 1,000 words, showing that the difference between males' and females' performance in VLT is statistically significant in favor of male subjects. Furthermore, the researcher maintained that "most of the students analyzed in the present study could have problems to understand written and spoken discourse in English due to their low scores in the receptive vocabulary level test" (p. 66).

In her study, Fontecha (2014) examined the relationship between the receptive vocabulary size and the motivation towards EFL learning. The aim of this exploration was threefold: (1) gender variation in EFL receptive vocabulary size, (2) gender variation in motivation towards EFL, and (3) whether there is any relationship between motivation towards EFL and the scores obtained by males and females in receptive vocabulary. The results showed females were more motivated with no significant difference in general motivation. However, significant differences are found in intrinsic motivation in favor of females. The findings also showed that females outperformed males in receptive vocabulary size but the difference between their mean scores is not significant. Furthermore, there was a significant positive correlation between females' performance in vocabulary size test and their extrinsic motivation.

Sungprakul (2016) investigated the vocabulary size of Thai university students. The aim was to "establish the number of English vocabulary in the first 10000 most occurring words list that Thai EFL students at the university level know receptively" (p. 1). Furthermore, the researcher intended to see whether or not the participants' word knowledge increases as they proceed in their study. The participants were 40 EFL learners from four different levels: first to fourth year of English Major at Silpakorn University in Thailand. Two sets of the XK_Lex test, a yes/no format of vocabulary test, were used in this study. The results showed that first year students hold a vocabulary knowledge of around 5800-5900 words from the first 10000 most frequent word list. The results also indicated that students possess more word knowledge as they move up to the higher year in the 
appropriate rate. That is the rate of vocabulary knowledge increasing gradually from year one to year four. In year one, the subjects maintain between 5,800 to 5,900 words in year one, 6300-6600 words in year two, 6500 to 7100 words in year three, and 7300 to 7400 for the senior year group in year four.

\section{The Present Study}

\subsection{Research Questions}

The aim of the present study is to answer the following two research questions:

1) What is the size of the receptive English vocabulary of the Saudi students towards the end of their undergraduate study?

2) Are there any differences in vocabulary size between male and female students?

\subsection{Participants}

Seventy-one male and female final year Saudi students (male 34, 48\% \& female 37, 52\%) participated in this study. They have studied English for almost five years (around 2300 teaching hours) as an English Language and Translation major in the Department of English and Translation in the College of Languages and Translation at King Saud University. The vocabulary size test was administered during regular classes and participation in this study was voluntary.

\subsection{Instrument}

Adopted from Nation (2008, pp. 177-302), the Vocabulary Levels Test (VLT) was used in this study. The VLT is a diagnostic test that assesses knowledge of English receptive vocabulary and it can be easily administered and scored. The words elicited in the test are based on an existing corpus and therefore represent an accurate profile of the words and their frequencies in natural use (Nation, 2013). When taking the test, the participants are required to match the target word with its definition. The test consists of five separate sections, which represent four levels of word frequencies as well as the Academic Word List (AWL). The test assesses learners' receptive knowledge of word meaning at the following distinct vocabulary levels: the $2^{\text {nd }} 1,000$-word level, the $3^{\text {rd }}$ 1,000 -word level, the $5^{\text {th }} 1,000$-word level, the $10^{\text {th }} 1,000$-word level, and AWL. Each level consists of 30 items representing the whole frequency level with a total of 150 words in the five parts of the complete test. Test items are similar to the following example:

1 birth

2 dust game

3 operation winning

4 row being born

5 sport

6 victory

Participants' test scores will be calculated and can therefore be looked at as an indication of whether learners have mastered the words in these levels of word families in English.

\subsection{Procedures}

The Vocabulary Levels Test (VLT) was administered by the researcher to the male participants and by a female colleague to the female participates in the female campus in the same week. The administration of the test took place a couple of weeks prior to the end of the participants' final semester. Oral instruction was given in Arabic to the participants before taking the test and there was no time limit to complete it. Participation was voluntary.

\subsection{Data Analysis}

Descriptive statistics were used to address the research questions of this study regarding the Saudi EFL university graduates' receptive vocabulary size and the differences that might exist between the performance of male and female participants in the different frequency levels of the test. Scores collected from this study were analyzed using the Statistical Package for Social Science (SPSS), by applying the T-Test to the data to get the means and standard deviations for each of the test items. As mentioned above, the 30 test items in each level are representative samples of a large group of words, thus, the test mean are indicative of an estimate of the participants' vocabulary size. If, for example, the overall score of the participants at the $3^{\text {rd }} 1,000$-word level is 15 out of 30 , then we will assume that they know 500 out of the 1000 words at that level. 


\section{Results}

The results of this study showed different participants' performance in different word levels with a decreasing mean score as the frequency of word levels decreased. That is, better performance with high frequency words. The results also showed, with no exception, that there were significant statistical differences between male and female scores in all five sections of the test. See Table 1 below.

Table 1. Descriptive statistics of participants' performance in all test levels

\begin{tabular}{|c|c|c|c|c|c|c|}
\hline Vocabulary Test Level & Gender & $\mathbf{N}$ & Max. mean score & Mean & Std. Deviation & Sig. \\
\hline \multirow[t]{2}{*}{$2^{\text {nd }} 1,000$-Word Level } & Male & 34 & 30 & 26.29 & 3.8575 & \multirow{2}{*}{$.021^{*}$} \\
\hline & Female & 37 & 30 & 23.97 & 4.3874 & \\
\hline \multirow[t]{2}{*}{$3^{\text {rd }} \quad 1,000$-Word Level } & Male & 34 & 30 & 21.76 & 7.0499 & \multirow{2}{*}{$.020^{*}$} \\
\hline & Female & 37 & 30 & 17.73 & 7.1595 & \\
\hline \multirow{2}{*}{$5^{\text {th }} \quad 1,000$-Word Level } & Male & 34 & 30 & 17.41 & 6.1552 & \multirow{2}{*}{$.030^{*}$} \\
\hline & Female & 37 & 30 & 14.30 & 5.6758 & \\
\hline \multirow[t]{2}{*}{$10^{\text {th }} 1,000$-Word Level } & Male & 34 & 30 & 7.62 & 5.505 & \multirow{2}{*}{$.000 * *$} \\
\hline & Female & 37 & 30 & 3.73 & 3.070 & \\
\hline \multirow[t]{2}{*}{ Academic Word List Level } & Male & 34 & 30 & 22.97 & 6.3508 & \multirow{2}{*}{$.007 * *$} \\
\hline & Female & 37 & 30 & 18.70 & 6.6285 & \\
\hline \multirow[t]{2}{*}{ Overall mean 30} & Male & 34 & 30 & 19.21 & 4.7357 & \multirow{2}{*}{$.002 * *$} \\
\hline & Female & 37 & 30 & 15.69 & 4.5337 & \\
\hline
\end{tabular}

\section{The $2^{\text {nd }} 1,000-$ Word Level}

Results in this level showed a mean score of 26.29 for male participants compared to 23.97 for female participants. In all test levels, each word represents 33.33 words (1000 divided by 30 ). This would give us an estimate of $876(87.6 \%)$ known words by male and 799 (79.9\%) words by female participants. Participants had the highest score under this level between male and female mean scores with a minimum significant difference at $p<0.05$.

\section{The $3^{\text {rd }} 1,000-$ Word Level}

The results here showed a mean score of 21.76 for male participants, as opposed to 17.73 for female participants. This would give us an estimate of $725(72.5 \%)$ known words by males and $590(59 \%)$ words by female participants. Participants had a noticeable drop in their scores in this level with a big difference/gap between male and female scores, which was statistically significant at $p<0.01$.

\section{The $5^{\text {th }} \mathbf{1 , 0 0 0 - W o r d ~ L e v e l ~}$}

The results under this band showed very low mean scores. The mean score for male participants was 17.41, while the mean score for female participants was 14.30. This may lead us to assume that the estimated known words by male participants are 580 (58\%) compared to 477 (47.7\%) known words by female participants. Again, participants had a noticeable drop in their vocabulary size in this level. Similar to the previous level, the difference/gap between male and female scores was statistically significant at $p<0.01$.

\section{The $10^{\text {th }} 1,000$-Word Level}

The results showed very poor performance by both genders as indicated by the very low mean scores. The mean score for male participants was 7.62, whereas the mean score for female participants was 3.73. These mean scores would give us an estimate of $254(25.4 \%)$ words known by male participants and 124 (12.4\%) words by female participants. The difference was again statistically significant at $p<0.01$.

\section{The Academic Word List Level (AWLL: 570 Word Families)}

The results showed an improvement in the male participants' performance compared to their performance in the previous word level with a mean score of 22.97. Likewise, there was an increase in the female participants mean score: 18.70. The estimated vocabulary size for this level is $436(76.5 \%)$ and $355(62.3 \%)$ words for male and female participants respectively. The difference between male and female scores was statistically significant at $p$ $<0.01$.

\section{Discussion}

Although it is stated that Saudi students are expected to leave high school with a vocabulary size of around 3000 words (Saudi Ministry of Education), this estimate of vocabulary size is questionable and not always true. As 
seen in the literature review, Al-Hazemi's (1993) results showed that learners post high school military cadets knew between 800 and 2000 words with an average mean score of around 1000 words. Al- Nujaidi's (2003) reached a similar conclusion, which is that first year Saudi university students score very poorly in vocabulary size tests. His results showed that the learners' average vocabulary size is approximately between 500 to 700 words at the 2000 and 3000 word levels and around 75 words at the academic vocabulary level. Unlike the above results, results from Al-Masrai and Milton's (2012) study, which was performed on second and final year students, revealed that learners knew approximately 2000 to 3000 of the most frequent 10,000 words of English when they enter university, and about 5000 words when they leave.

The current study is different from the above studies in its focus and scope in a number of ways. First, it tested receptive vocabulary near the time of graduation of a university program. Second, it had participants from both genders. Third, it covered five-word frequency levels as shown above. Consequently, the results should be looked at and interpreted differently. Table 2 below shows the number and percentages of known words under each frequency band for both male and female participants.

Table 2. Number and percentages of vocabulary size

\begin{tabular}{lllllll}
\hline Word Frequency Level & & $\mathbf{2}^{\text {nd }} \mathbf{1 , 0 0 0}-\mathbf{W L}$ & AWLL (570) & $\mathbf{3}^{\text {rd }} \mathbf{1 , 0 0 0}-\mathbf{W L}$ & $\mathbf{5}^{\text {th }} \mathbf{1 , 0 0 0 - W L}$ & $\mathbf{1 0}^{\text {th }} \mathbf{1 , 0 0 0}-\mathbf{W L}$ \\
\hline \multirow{3}{*}{$\begin{array}{l}\text { Number of known words } \\
\text { and percentages }\end{array}$} & \multirow{2}{*}{ Fale } & 876 & 436 & 725 & 580 & 254 \\
& & $87.6 \%$ & $76.5 \%$ & $72.5 \%$ & $58 \%$ & $25.4 \%$ \\
& & 799 & 355 & 590 & 477 & 124 \\
& & $79.9 \%$ & $62.3 \%$ & $59 \%$ & $47.7 \%$ & $12.4 \%$ \\
\hline
\end{tabular}

The results demonstrate a very strong frequency effect, where vocabulary knowledge is at its highest in the levels of high frequency bands. This effect is summarised in Table 2 and Figure 1.

As can be seen in Table 2, the results show a similar pattern, where males participants outperform the females with no exception. The differences are statistically significant in the five sections of the test. These results are in line with results from Canga Alonso's (2013) study, but they contradict the results from Fontecha (2014) where females outperform the males. Furthermore, the number of the known words by both genders decreases as the level of frequency decreases for the four frequency bands- $2^{\text {nd }} 1,000$-word level to $10^{\text {th }} 1,000$-word level. However, the decrease is slightly sharper for female participants. As expected, all participants had their highest scores in the $2^{\text {nd }} 1,000$-word level, which represents the band with the highest word frequency while their lowest scores came from the data under the $10^{\text {th }} 1,000$-word level, which represents the lowest word frequency band.

With the exception of the $10^{\text {th }} 1,000$-word level, it is evident from these figures that participants performed very well in the rest of the four word levels including AWL, showing a large vocabulary size within the first two frequency bands and a very acceptable size within the $5^{\text {th }} 1,000$-word level. The scores are also excellent in AWL. However, the overall vocabulary size (Male: 3201; Female: 2614) is below the desired level for graduate English major and the female participants' is short of the proposed figure of 3000 words for the vocabulary size of high school graduates. These results of overall poor performance are in conformity with the results of Al-Hazemi's (1993) and Al-Nujaidi's (2003) and again question the validity of that figure. It should be mentioned here that the vocabulary size of the participants in this study is higher than those in the previous two studies (Al-Hazemi 1993; Al-Nujaidi, 2003) and this should be due to the fact that our participants are near graduation from the program. Nonetheless, they are still far below the vocabulary size achieved by learners in the study of Al-Masrai and Milton's (2012) and Sungprakul's (2016). Al-Masrai and Milton maintained that their learners probably knew approximately about 5000 words of the most frequent 10000 words when they leave the university. In contrast, the participants of this study knew only about 3201 and 2614 words for male and female participants respectively. Sungprakul also reported that the rate of vocabulary knowledge increased gradually from year one to year four, from 5,900 words in year one to 7,400 words for the senior group in year four. 


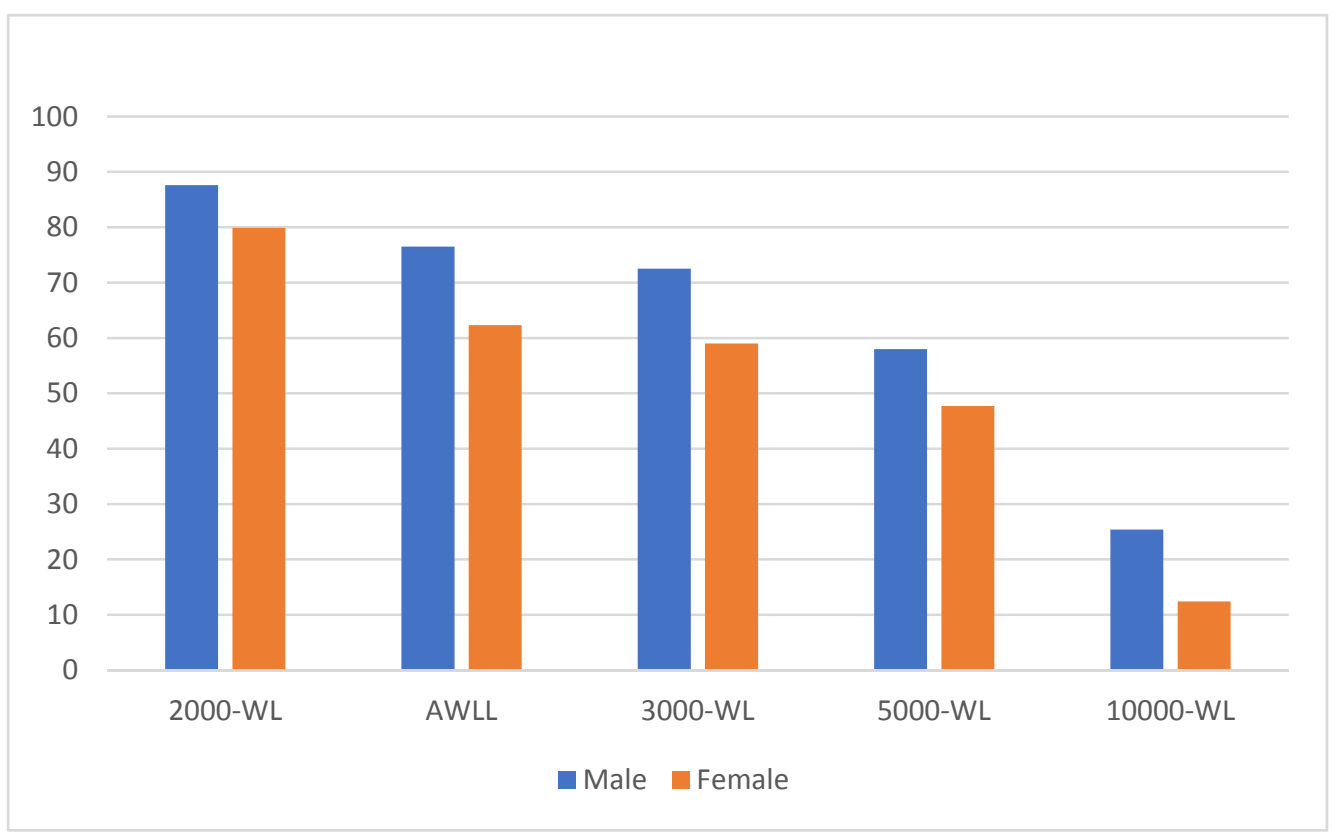

Figure 1. Percentages of male and female vocabulary size under different frequency bands

Nation (2008) described The Vocabulary Levels Test as a diagnostic test, as it tries to diagnose or find out which areas of vocabulary learners know or do not know well. Furthermore, he asserted that the test "was developed to find where learners' vocabulary needed attention" (p. 141). Using VLT, this study drew a picture that showed the lack of sufficient vocabulary knowledge for our EFL learners, even those who are majoring in English. That is, even though the subjects were in their final semester (level 10), with around 2300 contact hours of English classroom instruction, they still lacked the required vocabulary size needed under all the five sections of the VLT. This might be a result of poor EFL learning and teaching prior to university level. Nation (2008) argues that we would expect a learner to know at least 27 out of 30 words $(90 \%)$ of the words at any given level to be at a satisfactory level of performance. The highest percentage reached by the participants in the current study (87.6\%) is still short of the acceptable level of $90 \%$. This might indicate to us the difficulties that our EFL learners might face during their university studies as a result of deficiency.

Treffers-Daller and Milton (2013) maintained that recent research has provided some evidence that establish the sufficient number of words needed for different language tasks. They maintained that a learner needs 2,000-3,000 of the most frequent English words to participate effectively in everyday conversation, whereas 5,000 words are needed to begin to read authentic texts (cf. Schmitt 2007) and around 10,000 for starting an academic degree course (Hazenberg \& Hulstijn, 1996). Furthermore, after investigating the vocabulary size of a group of highly educated L2-users of English, Nation (2006) found that they knew around 8,000 to 9,000 word families. Considering these figures, the results of the current study suggest that the participants' vocabulary size is much smaller than is generally expected. An average figure of nearly 3200 of English words families near graduation from the English and Translation program would suggest that our EFL leaners can participate effectively in everyday conversation, but will struggle with tasks that require high level of language comprehension and production.

\section{Conclusion}

One cannot deny the advantage of having large vocabulary size and the crucial role it plays in EFL learning and recent studies have confirmed this conclusion (cf. Nation, 2006, 2013; Schmitt \& Schmitt, 2012). However, it is not easy to have a large vocabulary size. Meara (1980) has pointed out that "most learners identify the acquisition of vocabulary as their greatest single source of problems" (p.221). This study aimed to measure the receptive vocabulary knowledge of Saudi university students (male 34, \& female 37) towards the end of their final year with approximately 2300 contact hours of English learning. The Vocabulary Levels Test, adopted from Nation (2008), was administered during the last two weeks of their final semester. The results showed different participants' performances at different word levels with declining mean scores as the frequency of word levels declined. The participants' average vocabulary size is approximately 876 and 799 words in the $2^{\text {nd }} 1,000$-word 
level, 436 and 355 words in AWL, 725 and 590 words in the $3^{\text {rd }} 1,000$-word level, and 580 and 477 words in the $5^{\text {th }} 1,000$-word level for males and females respectively. However, the average vocabulary size decreased dramatically in the $10^{\text {th }} 1,000$-word level to 254 words for males and 124 for females. The results also showed, with no exception, that males outperformed females with statistically significant differences in all five sections of the test. It is concluded that Saudi English and Translation university graduates, even with large vocabulary sizes in the high frequency bands, are still generally below the level of the desired vocabulary competency as EFL learners, and, in fact, in need for more support and concentration classes in their undergraduate study. It is recommended that further studies should look at the vocabulary coverage of the whole program and the expected learned vocabulary by the end of it, and find out the causes of the mismatch between the expected outcome and the real vocabulary size.

\section{Acknowledgements}

The author would like to thank the Deanship of Scientific Research at King Saud University, for funding this research project.

\section{References}

Alderson, J. C. (2005). Diagnosing Foreign Language Proficiency: The Interface between Learning and Assessment. London; New York: Continuum.

Al-Hazemi, H. (1993). Low level EFL vocabulary tests for Arabic speakers. Unpublished doctoral dissertation. University of Wales, Swansea, UK.

Allen, V. F. (1983). Techniques in teaching vocabulary. New York: Oxford University Press.

Al-Masrai and Milton. (2012). The Vocabulary Knowledge of University Students in Saudi Arabia. TESOL Arabia Perspectives, 19(3), 13-19.

Al-Nujaidai, A. H. (2003). The Relationship between Vocabulary Size, Reading Strategies, and Reading Comprehension of EFL Learners in Saudi (Unpublished doctoral dissertation). Colorado State University: Fort Collins, Colorado.

Baleghizadeh, S., \& Golbin, M. (2010). The effect of vocabulary size on reading comprehension of Iranian EFL learners. Linguistic and Literary Broad Research and Innovation, 1(2), 33-46.

Beglar, D. (2000). Estimating vocabulary size Estimating vocabulary size. Shiken: JALT Testing \& Evaluation SIG Newsletter, 4(1), 2-4.

Canga Alonso, A. (2013). Receptive vocabulary size of secondary Spanish FL learners. Revista de Lingüistica y Lenguas Aplicadas, 8, 66-75. https://doi.org/10.4995/rlyla.2013.1180

Cooper, T. (1997). Assessing Vocabulary Size: So, what's the Problem? Language Matters: Studies in the Languages of Africa, 28(1), 96-117. https://doi.org/10.1080/10228199708566122

Coxhead, A., Nation, P., \& Sim, D. N. Z. J. (2015). Measuring the vocabulary size of native speakers of English in New Zealand secondary schools. New Zealand Journal of Educational Studies, 50(1), 121-135. https://doi.org/10.1007/s40841-015-0002-3

Fontecha, F. (2014). Motivation and gender-related variation in EFL vocabulary acquisition in primary education. ES. Revista de Filología Inglesa, 35, 89-112.

Gu, Y. (2010). Learning strategies for vocabulary development. Reflections on English Language Teaching, 9(2), 105-118.

Gyllstad, H., Vilkaite, L. \& Schmitt, N. (2015) Assessing vocabulary size through multiple choice formats: issues with guessing and sampling rates. ITL - International Journal of Applied Linguistics, 166(2), 278-306. https://doi.org/10.1075/itl.166.2.04gyl

Harmer, J. (1996). The practice of language teaching. London: Longman.

Harsch, C., \& Hartig, J. (2016). Comparing C-tests and Yes/No vocabulary size tests as predictors of receptive language skills. Language Testing, 33(4), 555-575. https://doi.org/10.1177/0265532215594642

Hui, D. (2004). Reflections on vocabulary size of Chinese university students. International Education Journal, 5(4), 571-581.

Kotchana, S., \& Tongpoon-Patanasorn, A. (2015). EFL Learners' Vocabulary Size: A Case in the Northeastern Region of Thailand. Asian Journal of Education, 1(1), 9-26. 
Kurniawan, I. (2016). Measuring EFL students' vocabulary size: why and how. English Education: Jurnal Tadris Bahasa Inggris, 9(1), 89-102.

Laufer, B., \& Goldstein, Z. (2004). Testing vocabulary knowledge: Size, strength, and computer adaptiveness. Language Learning, 54(3), 399-436. https://doi.org/10.1111/j.0023-8333.2004.00260.x

Laufer, B., \& Nation, P. (1999). A vocabulary-size test of controlled productive ability. Language Testing LANG TEST, 16, 36-55. https://doi.org/10.1191/026553299672614616

Marchman, V. A., Fernald, A., \& Hurtado, N. (2010). How vocabulary size in two languages relates to efficiency in spoken word recognition by young Spanish-English bilinguals. Journal of Child Language, 37(4), 817-840. https://doi.org/10.1017/S0305000909990055

Meara, P. (1980). Vocabulary acquisition: A neglected aspect of language learning. Language Teaching \& Linguistics, 13(3-4), 221-246. https://doi.org/10.1017/S0261444800008879

Meara, P., \& Alcoy, J. C. (2010). Words as species: An alternative approach to estimating productive vocabulary size. Reading in a Foreign Language, 22(1), 222-236.

Milton, J., \& Treffers-Daller, J. (2013). Vocabulary size revisited: the link between vocabulary size and academic achievement. Applied Linguistics Review, 4(1), 151-172. https://doi.org/10.1515/applirev-2013-0007

Nacera, A. (2010). Languages learning strategies and the vocabulary size. Procedia - Social and Behavioral Sciences, 2(2), 4021-4025. https://doi.org/10.1016/j.sbspro.2010.03.634

Nadarajan, S. (2007). Measuring Academic Vocabulary Size and Depth in the Writing Classroom: Does it Really Matter? Unpublished doctoral dissertation. University of Arizona: Tucson, Arizona.

Nation, I. S. P. (1982). Beginning to learning foreign vocabulary. RELC Journal, 13, 14-36. https://doi.org/10.1177/003368828201300102

Nation, I. S. P. (1983). Testing and Teaching Vocabulary. Guidelines, 12-25.

Nation, I. S. P. (1990). Teaching and Learning Vocabulary. New York: Newbury House.

Nation, I. S. P. (2006). How Large a Vocabulary Is Needed For Reading and Listening? Canadian Modern Language Review/La Revue Canadienne Des Langues Vivantes, 63(1), 59-82. https://doi.org/10.3138/cmlr.63.1.59

Nation, I. S. P. (2008). Teaching Vocabulary: Strategies and Techniques. Boston, USA: Heinle, Cengage Learning.

Nation, I. S. P. (2012). Measuring Vocabulary Size in an Uncommonly Taught Language. International Conference on Language Proficiency Testing in the Less Commonly Taught Languages, Bangkok, Thailand.

Nation, I. S. P. (2013). Learning vocabulary in another language. Cambridge, England: Cambridge University Press. https://doi.org/10.1017/CBO9781139858656

OLMOS, C. (2009). An assessment of the vocabulary knowledge of students in the final year of secondary education. Is their vocabulary extensive enough? IJES, Special Issue, 73-90.

Oxford, R. (1990). Language learning strategies: What every teacher should know. New York: Newbury House.

Özönder, Ö. (2016). Student EFL Teachers' Receptive Vocabulary Size. Procedia - Social and Behavioral Sciences, 232, 444-450. https://doi.org/10.1016/j.sbspro.2016.10.061

Pignot-Shahov, V. (2012). Measuring L2 receptive and productive vocabulary knowledge. Language Studies Working Papers, 4, 37-45.

Richard, J. C., \& Renandya, W. A. (2002). Methodology in Language Teaching. England: Cambridge University Press. https://doi.org/10.1017/CBO9780511667190

Schmitt, N. (2000). Vocabulary in language teaching. New York: Cambridge University Press.

Schmitt, N. (2010). Researching vocabulary: a vocabulary research manual. Houndmills, Basingstoke, Hampshire; New York: Palgrave Macmillan. https://doi.org/10.1057/9780230293977

Schmitt, N., \& Schmitt, D. (2012). A reassessment of frequency and vocabulary size in L2 vocabulary teaching. Language Teaching, 47, 484-503. https://doi.org/10.1017/S0261444812000018 
Schmitt, N., Schmitt, D., \& Clapham, C. (2001). Developing and exploring the behaviour of two new versions of the Vocabulary Levels Test. Language Testing, 18(1), 55-88. https://doi.org/10.1177/026553220101800103

Şen, Y., \& Kuleli, M. (2015). The Effect of Vocabulary Size and Vocabulary Depth on Reading in EFL Context. Procedia - Social and Behavioural Sciences, 199, 555-562. https://doi.org/10.1016/j.sbspro.2015.07.546

Staehr, L. S. (2008). Vocabulary Size and the Skills of Listening, Reading and Writing. Language Learning Journal, 36(2), 139-152. https://doi.org/10.1080/09571730802389975

Sungprakul, S. (2016). Measuring Vocabulary Size of Thai University Students. International Journal of Social Science and Humanities Research, 4(4), 608-624.

Szabo, C. Z. (2016). Exploring the Mental Lexicon of the Multilingual: Vocabulary Size, Cognate Recognition and Lexical Access in the L1, L2 and L3. Eurasian Journal of Applied Linguistics, 2(2), 1-25. https://doi.org/10.32601/ejal.461007

Tanabe, M. (2016). Measuring second language vocabulary knowledge using a temporal method. Reading in a Foreign Language, 28(1), 118-142.

Treffers-Daller, J., \& Milton, J. (2013). Vocabulary size revisited: the link between vocabulary size and academic achievement. Applied Linguistics Review, 4(1), 151-172.

Tseng, W. T. (2016). Measuring English vocabulary size via computerized adaptive testing. Computers \& Education, 97, 69-85. https://doi.org/10.1016/j.compedu.2016.02.018

Waldvogel, A. D. (2013). The relationships between vocabulary learning strategies and vocabulary size among adult Spanish foreign language learners. Journal of Language Teaching and Research, 4(2), 209-219. https://doi.org/10.4304/jltr.4.2.209-219

Wilkins, D. (1972). Linguistics in Language Teaching. London: Edward Arnold.

Wilson, S., Thorne, A., Stephens, M., Ryan, J., Moore, S., Milton, M., \& Brayley, G. (2016). English Vocabulary Size in Adults and the Link with Educational Attainment. Language in Focus Journal, 2(2), 44-96. https://doi.org/10.1515/lifijsal-2016-0008

Zimmerman, K. (2005). Newly placed versus continuing students: Comparing vocabulary size. TESL Reporter, $38(1), 52-60$.

\section{Copyrights}

Copyright for this article is retained by the author, with first publication rights granted to the journal.

This is an open-access article distributed under the terms and conditions of the Creative Commons Attribution license (http://creativecommons.org/licenses/by/4.0/). 